\title{
Analysis of Bioactive Compounds from Different Algae Samples Extracted with Ultrasound: Characterizations, Phytochemical Contents and Antioxidant Potentials
}

\author{
Jakpa Wizi , Lixiao Ni*, Williams Kweku Darkwah, Li Xianglan
}

\section{Jakpa Wizi , Lixiao Ni*, Williams Kweku Darkwah, Li Xianglan}

Key Laboratory of Integrated Regulation and Resource Development on Shallow Lakes, MOE; School of Environment, Hohai University, Nanjing, CHINA.

\section{Correspondence}

Prof. Lixiao Ni

Key Laboratory of Integrated Regulation and Resource Development on Shallow Lakes, MOE; School of Environment, Hohai University, 210098 Nanjing, CHINA. Email id:20040051@hhu.edu.cn

\section{History}

- Submission Date: 01-10-2021;

- Review completed: 22-10-2021;

- Accepted Date: 02-12-2021

DOI : 10.5530/pres.14.1.7

Article Available online http://www.phcogres.com

\section{Copyright}

(c) 2022 Phcog.Net. This is an openaccess article distributed under the terms of the Creative Commons Attribution 4.0 International license.

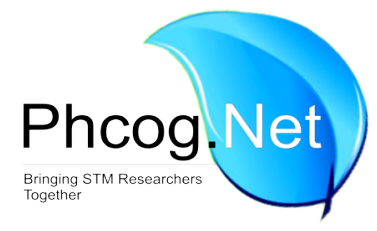

\begin{abstract}
Introduction: Algae are a significant bioactive compounds source, with variation in biological functions including antioxidant, anti-inflammatory and antiviral. Both microalgae and macroalgae biomass are a rich source of high value nutraceuticals and other bio products of commercial value, making algae worth investigating into. Objectives: To analyze bioactive phytochemicals and their antioxidants properties of extracts from algae from lake Taihu, Microcystis aeruginosa, Spirogyra and Seaweed extracted with ultrasound assisted method in comparison to the traditional extraction method, and a subsequent use of the residue in producing biochar. Materials and Methods: The different algae species viz Microcystis aeruginosa, Spirogyra and Seaweed were subjected to ultrasonic and thermostatted water bath extraction with a $70 \%$ ethanol and $30 \%$ water $(\mathrm{v} / \mathrm{v})$ as solvent. The extracts were characterized using gas chromatography-mass spectrometry. The total phenol and flavonoid and antioxidant activities were assessed in vitro viz hydroxyl radical $(\bullet \mathrm{OH})$ scavenging activity, ferric- reducing antioxidant property, total antioxidant capacity and 1, 1-diphenyl-2-picrylhydrazyl (DPPH) activity. Results: The chemical analysis indicated the existence of bioactive compounds such as alkaloids, phenols, tannins, flavonoids, terpenoids, steroids, proteins, carbohydrates, phytosterols, quinones, saponins, coumarins and glycosides. In vitro screening of the extracts also showed good antioxidant capacity (hydroxyl radical $(\bullet \mathrm{OH})$ scavenging activity, ferricreducing antioxidant property, total antioxidant capacity and 1, 1-diphenyl-2-picrylhydrazyl (DPPH) activity), the extracted compounds are of biological and pharmacological importance. The ultrasound assisted extraction method significantly increased yield with $27.0 \%$ in comparison to conventional method with $18.6 \%$. Conclusion: The study showed the different algae species were enriched with phytochemicals and that the ultrasound assisted method was an effective extraction method environmentally benignant. A complete utilization of algae biomass was achieved after biochar was made from the residue.
\end{abstract}

Key words: Algae species, Ultrasound assisted extraction, Ethanol, Phytochemicals, Antioxidant activity.

\section{INTRODUCTION}

The quest for alternate sources for the rise in demand for basic necessities such as food, quality water, energy, drugs and other resources arising from increasing world population has necessitated a search into underutilized and abundant resources. Algae is gaining popularity in the scientific community as a rich resource from which much benefit could be obtained to cope with the high demand. Algae are ubiquitous in nature with various types, mostly found in fresh water, seawater, hot springs, saline and hypersaline lakes, desert and even in the arctic ecosystem. ${ }^{[1,2]}$ Algae contains chlorophyll like other plants but lacks the well-defined plant features like leaves, roots, vascular tissue, and stems. They are a complex group that can manifest themselves in a variety of species and strains that are almost infinite and are classified under microalgae and macroalgae. Examples of microalgae species which are unicellular organisms includes Chlorella and Spirulina, whereas that of macroalgae which are multicellular organisms are seaweeds. The role of algae in aquatic environments is critical. In photosynthesis, they are able to turn water and carbon dioxide into sugar and produce oxygen as a byproduct, ${ }^{[3]}$ and have a fast growth rate surviving in harsh conditions. Algae are ecologically important in waterways and have a direct effect on the benefits people receive from these habitats.

Various studies have demonstrated the potential use of algae as a reliable and renewable feedstock for the development of biofuels such as biodiesel, bioethanol, and biomethane, as well as other valuable bioresources such as polysaccharides, proteins, enzymes, lipids, vitamins, and carotenoids 
and could find application in various industries. ${ }^{[4]}$ Algae has a significant appeal as a safe source of bioactive molecules to serve as antimicrobial, anti-carcinogenic, antioxidants and anti-inflammatory medicines. Natural products for treatment and health benefits can be traced throughout human development and a number of different plants and algae species have been used in this regard, as these natural products are rich with bioactive compounds. The global algae industry generates about 7,000 dry tons of algae biomass per year, and valued between $\$$ 3.8 - 5.4 billion dollars. ${ }^{[5]}$ These statistics indicate that the microalgae industry is growing in popularity around the world and that it will be widely used in the future as it penetrates consumer products in a variety of sectors.

Algae is promising because it provides an abundant source of bioactive compounds such as carotenoids, long chain polyunsaturated fatty acids, sterols, vitamins, polyphenols, phytochemicals, and other compounds that are of concern for health benefits. ${ }^{[3]}$ The scientific community has confirmed that carotenoids can protect against some cardiovascular diseases, age related eye disorders and cancers. LongChain Polyunsaturated Fatty Acids finds application as food additive and sterols can be used in healthy diets, especially those aimed at reducing coronary heart disease. ${ }^{[6]}$ Polyphenols are a form of antioxidant that protect cells and other natural body tissues from free radical.

The growing demand for bioactive compounds derived from natural sources necessitates the development of effective and efficient extraction methods. In manufacturing, a solvent-extraction technique is widely used. The food, pharmaceutical, and dye industries would benefit from a more effective solid-liquid extraction process for natural bioactive compounds. ${ }^{[7]}$ Extraction methods that are environmentally friendly and healthy have been mentioned in some studies. According to Duval et al., (2016). ${ }^{[8]}$ Pressurized gases, ultrasound, and microwave methods are among the most efficient extraction methods. Traditional extraction methods rely on the use of a suitable solvent to remove compounds from plant tissues. The choice of an effective solvent in conjunction with adequate mechanical agitation determines the mass transfer processes and the resulting performance of the extraction process. Phenolic compounds extraction in industry, makes use of water and ethanol for been environmentally benignant solvents. From sorghum pericarp, the study by, ${ }^{[9]}$ increased phenolic compounds extracted with ethanol/water and water as solvents at high temperature.

Hou et al., (2016), used ethanol/water as solvent to improved phenolic compounds extraction yield with ultrasound-assisted method. ${ }^{[10]}$ Akogou et al., (2017), indicated that prospective studies could concentrate on enhancing the methods for biocolorants extraction. ${ }^{[11]}$ The ultrasound assisted method (UAM); a promising technology was successfully employed in extracting compounds. To leach natural colorant, ${ }^{[12]}$ used ultrasonic method and magnetic stirrer, ultrasound greatly increased colorant extraction from plants. An earlier study by, ${ }^{[13]}$ successfully used UAM to extract pomegranate seed oil, it led to little composition modification of fatty acid.

This study seeks to analyze and improve bioactive compounds leached from different algae samples with ultrasound-assisted extraction method, a green technology in comparison to the traditional solvent extraction method and a subsequent test for phytochemicals, antioxidant activity and their quantitative analyses. The study also investigates the effect of different temperatures, power setting, exposure time and frequency on the yield and phytochemicals content of different algae species and their antioxidant activities assessed in vitro viz hydroxyl radical $(\cdot \mathrm{OH})$ reducing ability, ferric-reducing antioxidant property (FRAP), and 1, 1-diphenyl-2-picrylhydrazyl (DPPH) activity and total antioxidant capacity. The study also made use of the residue after extraction in producing biochar. The results could promote and add value to the different algae species for industrial application and their extract in the food and health sector.

\section{MATERIALS AND METHODS}

\section{Plant materials obtained}

Microalgae samples were obtained from Changzhou Taihu Lake and Wuxi Liangxi River, the algae species found in Taihu consist of Microcystis aeruginosa, Microcystis flos-aquae, Microcystis ichthyoblabe, Cyclotella, Cryptomonas, Navicula sp. and Scenedesmus as the dominant species, ${ }^{[14]}$ Spirogyra (genus spirogyra) was obtained from Xuanwu Lake in Nanjing, seaweed-Wakame (Undaria pinnatifida) samples were obtained from Fujian. Cultured algae (CA) samples (Microcystis aeruginosa) were obtained from Wuhan biotech institute. The samples were cleaned, oven dried and pulverized using a universal disintegrator.

\section{Chemicals}

Dragendorff's reagent, Hydrochloric acid $(\mathrm{HCl})$, sulfuric acid $\left(\mathrm{H}_{2} \mathrm{SO}_{4}\right)$, Ascorbic acid $\left(\mathrm{C}_{6} \mathrm{H}_{8} \mathrm{O}_{6}\right)$, sodium carbonate $\left(\mathrm{Na}_{2} \mathrm{CO}_{3}\right)$, sodium hydroxide, ferric chloride $\left(\mathrm{FeCl}_{3}\right)$, ferrous sulphate, acetic acid, sodium phosphate, potassium alum and gallic acid. All of the chemicals were of pure analytical grade. In the experiment, deionized water was used.

\section{Ultrasonic Assisted Extraction of bioactive compounds}

In this study, the conventional method (CM) of extraction was used alongside for comparison with Ultrasonic assisted method (UAM) in extracting bioactive compounds from different algae materials using solvents and different extraction conditions to ascertain their impact on the yield. The thermostatted water bath (Rapid Precision Machinery) was used to extract samples for the conventional method.

For the UAM, extraction of algae samples was with an ultrasound instrument (Ningbo Licheng Co. Ltd., China) with ultrasound frequency at $25 \mathrm{KHz}$. The extraction solvent's property is vital in the extraction process. Ethanol/water mixture was used as solvent for been benignant and promote effective recovery. ${ }^{[8]} \mathrm{A}$ solvent mixture of $70 \%$ ethanol and $30 \%$ water $(\mathrm{v} / \mathrm{v})$ was for the extraction.

The various algae samples were cleaned, oven dried and pulverized with a universal disintegrator (Yongshi jiupin company, China). To achieve the optimum extraction condition, the algae powder was introduced to the solvent and compounds leached at various temperatures $\left(45^{\circ} \mathrm{C}, 55^{\circ} \mathrm{C}\right.$, and $65^{\circ} \mathrm{C}$ ) and times (20 and $30 \mathrm{~min}$ ) using ultrasound power $70 \%$ and $30 \%$.

The sample extraction using the Conventional method was at $80^{\circ} \mathrm{C}$ for $60 \mathrm{~min}$. Temperature, ultrasonic power treatment, and time were set for each extraction condition for UAM. Each extraction condition was replicated three times and a thermometer was placed in the mixture to determine temperature. During the UAM extraction the input power was thought to be transformed into heat and dispersed in the medium.

The liquor extract was centrifuged at $3000 \mathrm{rpm}$ for $5 \mathrm{~min}$ with a tabletop high-speed Bioridge (TG16-WS) centrifuge. The supernatant was condensed in an evaporator to extract ethanol and water. To guarantee that all soluble bioactive substances were recovered, the residue was re-extracted. A freeze dryer was used to dry the concentrated extracts. The yield for each form was calculated using the equation below

$$
\text { Yield }(\%)=\frac{\text { Mass of extract }}{\text { Mass of sample used }} \times 100
$$


Wizi, et al.: Analysis of Bioactive Compounds from Different Algae Samples

\section{Characterization}

\section{Morphology of Algae samples}

The morphologies of different algae samples and extracts were examined with a HITACHI S-4800 (SEM, Japan). The algae samples were affixed using a conductive adhesive tape and sputter coated with gold palladium before being viewed at a $3 \mathrm{kV}$ accelerating voltage. The initial scale was magnified by 3000 times.

\section{Algae extracts chemical composition and UV-visible spectroscopy}

A Fourier-transform infrared spectrophotometer was used to assess the FTIR spectrum of different algae samples (Nicolet iS10, USA). Using the Attenuated Total Reflection (ATR) process, the extract was captured from 4000 to $500 \mathrm{~cm}^{-1}$. The absorbance was determined using a UV-Vis spectrophotometer (V-1200, Mapada instruments).

\section{Algae extract of Thermogravimetric analysis (TGA)}

The TGA of various algae extract was conducted in a nitrogen atmosphere using a $60 \mathrm{ml} / \mathrm{min}$ flow rate on a thermogravimetric analyzer TGA/SDTA 851e (Netzsch sta 449F5, Germany). The algae samples were subjected to heat at a rate of $20^{\circ} \mathrm{C} / \mathrm{min}$ from $30^{\circ} \mathrm{C}$ to $790^{\circ} \mathrm{C}$.

\section{Phytochemical Screening \\ Qualitative analysis}

The crude ethanolic extracts of the various samples were assayed for the content of alkaloids, tannins, glycosides, saponins, flavonoids, phenols, Quinones, protein, Coumarins, Carbohydrates, Phytosterols and terpenoids. The presence of phytochemicals is indicated by $(+)$ and the absence of phytochemicals is indicated by (-). Standard protocols were used in indicating the presence or absence of each compound. ${ }^{[15,16]}$ The analyzed samples include that of the conventional extract and ultrasonic method.

\section{Quantitative Analysis of Algae samples Total phenolic content analysis}

To determine total phenol, Folin-Ciocalteu assay described by, ${ }^{[16]}$ was used. $2.5 \mathrm{~mL}$ Ciocalteu's solution (10\% Folin) and $0.5 \mathrm{~mL}$ extract were mixed. $2.5 \mathrm{~mL}$ of 7.5 percent sodium carbonate solution was added. The mixture was incubated for $45 \mathrm{~min}$ at $45^{\circ} \mathrm{C}$, with absorbance taken at $760 \mathrm{~nm}$. Gallic acid $(0-100 \mathrm{~g} / \mathrm{mL})$ was used as standard in the calibration plot. The total phenolic content of the extract was measured in milligrams of gallic acid equivalents (GAE).

\section{Total alkaloids evaluation}

A gram of algae samples was placed in a beaker $(250 \mathrm{~mL}), 40 \mathrm{~mL}$ of $10 \%$ acetic acid/ethanol was introduced, the solution was sealed and left for four hours before being filtered and condensed to a quarter of its initial amount on a water bath. Until the precipitation was complete, drops of concentrated ammonium hydroxide were applied to the extract. Precipitate was separated, rinsed using diluted ammonium hydroxide, and sifted after solution had settled.

The absorbance was assessed at $512 \mathrm{~nm}$ after $30 \mathrm{minu}$ incubation in the dark. The calibration was created with gallic acid as standard. Using an average of three measurements, total alkaloid content was obtained in mg of Gallic acid equivalents (GAE). The alkaloid residue was dried and analyzed. ${ }^{[15]}$

\section{Total flavonoid evaluation}

Total flavonoid amount was assessed per the procedure by ${ }^{[17]}$ with minor modification. After diluting $0.25 \mathrm{~mL}$ sample to $1.25 \mathrm{~mL}$ with distilled water, $75 \mathrm{~mL}$ of $5 \%$ sodium nitrite was added, followed by $0.15 \mathrm{~mL}$ of $10 \%$ aluminum chloride solution after six minutes. After five minutes, $0.5 \mathrm{ml}$ of $0.1 \mathrm{M} \mathrm{NaOH}$ was added, then $2.5 \mathrm{ml}$ distilled water. With normal Gallic acid, absorbance was taken at $510 \mathrm{~nm}$. The results were analyzed in $\mathrm{mg}$ of gallic acid-equivalent flavonoids per gram of material.

\section{Total Tannins Content (TTC)}

To evaluate the phenolic content of Tannins, the ${ }^{[18]}$ approach was used. $1 \mathrm{~mL}$ extract was combined with $1 \mathrm{~mL}$ distilled water. $0.5 \mathrm{~mL}$ Folin's phenol (1:2) was applied, then $5 \mathrm{~mL} 35 \%$ sodium carbonate, and the mixture was allowed to sit for $5 \mathrm{~min}$. At $640 \mathrm{~nm}$, the color intensity was measured. The overall tannin content was measured in milligrams per gram of extract.

\section{Saponin determination}

The saponin content of various algae samples was determined using a modified version of the method. ${ }^{[19]}$ In $50 \mathrm{~mL}$ of $2 \%$ ethanol, $2 \mathrm{~g}$ of plant sample was dispersed. The mixture was heated for four hours in water bath at $55^{\circ} \mathrm{C}$ with constant stirring. The residue was re-extracted with additional $50 \mathrm{~mL} 2 \%$ ethanol. The mixture was reduced to $40 \mathrm{~mL}$ in water bath at $90^{\circ} \mathrm{C}$. The extract was transferred to a $250 \mathrm{~mL}$ separating funnel, $2 \mathrm{~mL}$ diethyl ether added and vigorously shaken. The aqueous layer was kept while ether layer discarded. The purifying procedure was carried out once more. $6 \mathrm{~mL}$ of normal butanol extracts were rinsed twice with $10 \mathrm{~mL} \mathrm{5 \%} \mathrm{NaCl}$ aqueous solution, and heated in water bath. The sample was oven-dried. The results were expressed as a percentage of total saponin.

\section{Total Antioxidant ability assays}

The phosphomolybdenum method with the technique of, ${ }^{[20]}$ was employed to determine antioxidant activity. A reagent solution was made with ammonium molybdate $(4 \mathrm{mM})$, sodium phosphate $(28 \mathrm{mM})$, and sulfuric acid $(0.6 \mathrm{M})$ which was combined in a $1: 1: 1$ ratio. $0.3 \mathrm{~mL}$ of each of the extract concentrations $(0.02-0.1 \mathrm{mg} / \mathrm{mL})$ which was mixed with $3 \mathrm{~mL}$ reagent. The reaction solution tubes were incubated at $95^{\circ} \mathrm{C}$ for $60-90 \mathrm{~min}$. After cooling, absorbance was taken at $695 \mathrm{~nm}$ against blank. Concentrations of $0.02-0.1 \mathrm{mg} / \mathrm{mL}$ of gallic acid were used as the standard. Triplicate of each concentration were made. $0.3 \mathrm{~mL}$ ethanol was added to $3 \mathrm{~mL}$ reagent as the blank.

\section{Ferric reducing antioxidant property (FRAP assay)}

Potassium ferricyanide, trichloroacetic acid, and ferric chloride can produce a color complex when mixed with antioxidant substances and measured at a wavelength of $700 \mathrm{~nm}$. The reaction mixture's increased absorbance suggests that these various algae extracts may be used as antioxidants, The algae sample extract's ability to minimize ferric ions was determined per the method by, ${ }^{[21]} 1.0 \mathrm{~mL}$ of varied doses $(0.02-0.10 \mathrm{mg} / \mathrm{mL})$ of extract and standards were mixed with $2.5 \mathrm{~mL}$ of $0.2 \mathrm{M}$ phosphate buffer $(\mathrm{pH} 6.6)$ and $2.5 \mathrm{~mL}$ of $\mathrm{K}_{3} \mathrm{Fe}(\mathrm{CN}) 6(1 \% \mathrm{w} / \mathrm{v})$. Before adding $2.5 \mathrm{~mL}$ trichloroacetic acid (TCA) $(10 \% \mathrm{w} / \mathrm{v})$ to the mixture, it was heated for $20 \mathrm{~min}$ at $50^{\circ} \mathrm{C}$ and centrifuged for $10 \mathrm{~min}$ at $3000 \mathrm{rpm} .0 .5 \mathrm{~mL} \mathrm{FeCl}_{3}(0.1$ percent w/v) was mixed with $2.5 \mathrm{~mL}$ supernatant and $2.5 \mathrm{~mL}$ distilled water, and the absorbance compared to a blank sample containing phosphate buffer at $700 \mathrm{~nm}$. The extract has a higher reducing strength when a higher absorbance of the mixture is recorded.

\section{Determination of 1,1-diphenyl-2-picrylhydrazyl (DPPH)}

The potential of natural substances to scavenge free radicals was assessed using DPPH radical scavenging test. The assay is focused on determining the antioxidant substances' ability to absorb free radical. With slight 
modifications, the free radical scavenging activity of the various algae extracts were assessed as defined by. ${ }^{[22]}$ A reaction mixture had $1.0 \mathrm{~mL}$ extracts and standard (gallic acid) in varying concentrations (0.02-0.10 $\mathrm{mg} / \mathrm{mL})$ as well as $1.0 \mathrm{~mL}$ DPPH solution $(0.135 \mathrm{mM})$. The solution was vigorously agitated before being placed in the dark for half an hour and read at $517 \mathrm{~nm}$ against ethanol as blank. All the reading were in triplicate. The percentage inhibition of oxidation was determined with the equation below:

$$
\text { DPPH scavenging activity }(\%)=\left(\frac{\mathrm{A}_{0}-\mathrm{A}_{1}}{\mathrm{~A}_{0}}\right) \times 100
$$

Whereas $\mathrm{A}_{0}$ represents blank, $\mathrm{A}_{1}$ represents extract's absorbance.

\section{Determination of Hydroxyl radical}

The different algae extracts' hydroxyl radical activity was calculated with modification per the method by, ${ }^{[23]} 0.5 \mathrm{~mL}$ extracts and Gallic acid at varying concentrations $(0.02-0.10 \mathrm{mg} / \mathrm{mL}), 1.0 \mathrm{~mL}$ iron-EDTA $(0.13 \%$ ferrous ammonium sulphate and 0.26\% EDTA), $0.5 \mathrm{~mL} 0.018 \%$ EDTA, and $1.0 \mathrm{~mL}$ DMSO $(0.85 \%$ in $0.1 \mathrm{~mole} / \mathrm{L}$ phosphate buffer $\mathrm{pH} 7.4)$ were used in the reaction mixture. The reaction starts when $0.5 \mathrm{~mL}$ ascorbic acid $(0.22 \%)$ is added and incubate for $5 \mathrm{~min}$ at $80^{\circ} \mathrm{C}$ to $90^{\circ} \mathrm{C}$. The reaction was halted when $0.1 \mathrm{~mL}$ ice-cold TCA (17.5\%) was added to the mixture. $3.0 \mathrm{~mL}$ Nash reagent $(75.0 \mathrm{~g}$ ammonium acetate, $3.0 \mathrm{~mL}$ glacial acetic acid, $2.0 \mathrm{~mL}$ acetyl acetone, and distilled water to a total volume of $1 \mathrm{~L}$ ) was introduced and incubated for $15 \mathrm{~min}$ for color development. At $412 \mathrm{~nm}$, the strength of the produced yellow color was compared to a reagent blank that included all of the constituents except ascorbic acid. The test was carried out in triplicate.

$$
\text { hydroxyl scavenging activity }(\%)=\left(\frac{a-b}{a}\right) \times 100
$$

Whereas a indicates control sample and b indicates test sample absorbance.

\section{GC-MS analysis and Biochar production}

The compounds from different algae species were identified using GC-MS method. The peaks were identified based on comparing the obtained mass spectra with those available in NIST library. Biochar produced from the residue after extraction was done according to the method. ${ }^{[24]}$

\section{RESULTS AND DISCUSSION}

\section{Extract yield for different algae samples extracted with Ultrasonic method}

The yield for the different algae samples extracted with the ultrasonic method are shown in Table 2. The ultrasound method had better results for all algae sample when compared with conventional method with the yield of $18.6 \%$. The highest yield among the algae samples was that of Changzhou sample with $27.0 \%$, spirogyra sample recorded the lowest $19.5 \%$ with UAM and yet better than that of the conventional method.

The improvement in yield for the ultrasound method resulted from the acoustic cavitation by ultrasound through the liquid which increased the rupturing of algae cell wall when the bubbles violently collapse creating intense pressure about $10^{3}$ bar. $^{[25]}$ at the surface of the solid matrix and increased contact between compounds and solvent resulting in solubility of compounds and their transport into medium. ${ }^{[25]}$ The extraction medium also provides an additional extraction power to the whole extraction process with its ability to leach compounds, both ethanol and water-soluble compounds were accessed after the rupturing of cell wall by sonication hence the increase in yield. The difference in yield among various algae samples extracted with ultrasound can be attributed to each algae species growth environment, composition, type and quantity and polarity of compounds present. ${ }^{[26]}$

The absorbance curves for different algae samples extracted by ultrasound method are shown in Figure 1. From the curve, Changzhou sample showed the maximum absorption in the visible wavelengths range of 400-800 $\mathrm{nm}$ followed by Spirogyra sample. The higher absorption indicates the extract had higher content of biocolorants. ${ }^{[7]}$

\section{Phytochemical screening}

The phytochemical screening of crude ethanolic extracts of various algae samples identified some secondary metabolites such as alkaloids, phenols, tannins, flavonoids, terpenoids, steroids, proteins, carbohydrates, phytosterols, quinones, coumarins and glycosides which agrees with, ${ }^{[27]}$ as shown in Table 1.

Quinones and Coumarins were absent in seaweed extracts and were detected in all other algae samples. The phytochemical compounds like phenolic, alkaloids, flavonoids and tannins detected are known to have antioxidant potential and can help in controlling several ailments, ${ }^{[16]}$ and their presence showcases these algae as potential sources worth investing into.

The optimized extraction condition used for extracting different algae samples were $55^{\circ} \mathrm{C}, 30$ mins and power setting of $70 \%$, which evidently saved time. The optimal condition was settled on after different temperature, time and power setting were used extraction to determine the favorable condition. The viscosity of liquid solvents is reduced at high temperatures, making it easier to penetrate the matrix and extract more compounds, ${ }^{[28]}$ cavitation is easier to produce at higher liquid temperatures. The vapor pressure in the bubbles rises when the temperature rises too high. As a result, as the bubble closes, the buffer action increases while cavitation decreases. Ethanol is more likely to volatilize as the temperature with the liquid increases.

\section{Total Phenolic Content}

Phenols are phytochemical component that plays an essential role in reducing free radicals in the body. The extraction method together with the extraction solvent plays a role in having more phenolic compounds transferred. The ultrasound method improved amount of total phenol

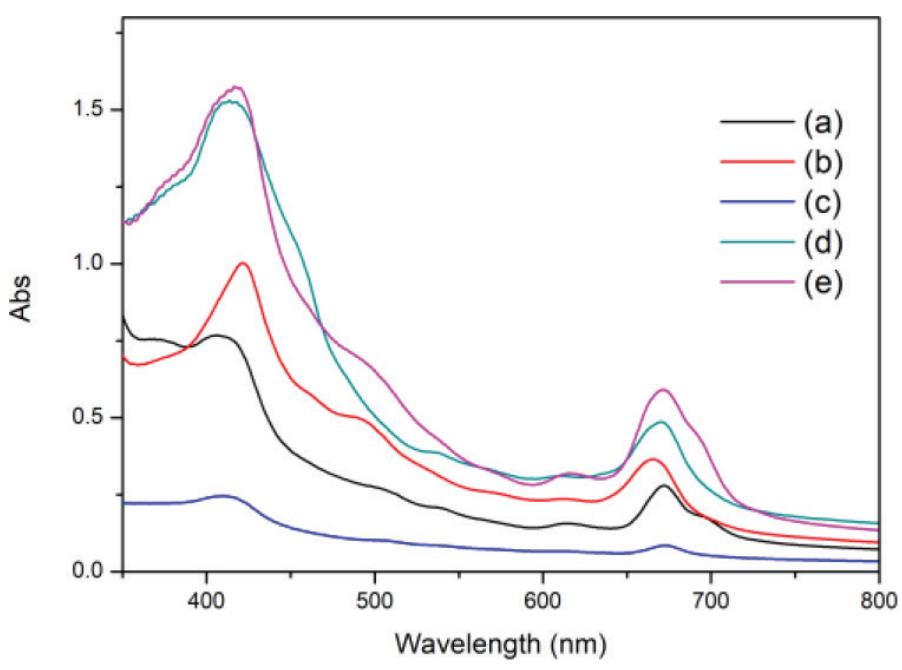

Figure 1: The absorbance curves of different algae extracted by UM method. (a) Wuxi sample (b) Cultured algae (c) Seaweed (d) Spirogyra (e) Changzhou sample. 
content for all algae samples as compared to the conventional method and this can be attributed to the impact cavitation had on the cell containing compounds and their solubility in the extraction solvents (Table 2) The possible redox of phenol composites enables them to function as reducing agents, as hydrogen donors, as singlet oxygen quencher and as a metal chelator. ${ }^{[29]}$

Table 2 indicates the highest extract yield for the Changzhou sample and is not the highest with total flavonoid content and has a slightly higher phenol content than the Wuxi sample. This non-correlation between extract yield and flavonoid content and phenol content can be due to other substances, such as peptides, fatty acids, carbohydrates, pigments and soluble proteins. ${ }^{[30]}$ The Folin-Ciocalteu reagent used to quantify Phenol Content essentially measures the reduction ability of the sample and measured other non-phenolic substances with reducing capacity, such as sugars and proteins, peptides and amino acids. ${ }^{[31]}$ Consequently, non-flavonoid impurities may interfere with the aluminum chloride reagent for the determination of flavonoid content, resulting in a significant bathochromic shift and a reduction in the sample's flavonoid content measured.

Table 1: Qualitative analysis of UAM extracted algae samples indicating the presence or absence of phytochemicals.

\begin{tabular}{|c|c|c|c|c|c|c|}
\hline \multirow[b]{2}{*}{ Phytochemicals } & \multicolumn{6}{|c|}{ Algae sample } \\
\hline & 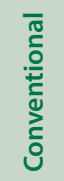 & 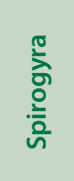 & 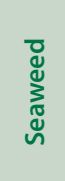 & 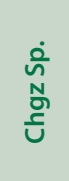 & $\begin{array}{l}\text { ํㅡㅁ } \\
\dot{x} \\
3\end{array}$ & $\varangle$ \\
\hline Alkaloids & +++ & +++ & +++ & +++ & +++ & +++ \\
\hline Saponins & +++ & + & ++ & +++ & + & ++ \\
\hline Glycosides & +++ & +++ & ++ & +++ & +++ & +++ \\
\hline Tannins & + & ++ & + & + & + & + \\
\hline Phenols & + & ++ & + & ++ & + & + \\
\hline Flavonoids & + & ++ & +++ & +++ & + & ++ \\
\hline Terpenoids & +++ & +++ & - & +++ & + & + \\
\hline Proteins & +++ & +++ & + & +++ & ++ & +++ \\
\hline carbohydrates & ++ & ++ & +++ & +++ & +++ & +++ \\
\hline Phytosterols & ++ & +++ & + & +++ & +++ & +++ \\
\hline Quinones & ++ & ++ & - & +++ & ++ & + \\
\hline Coumarins & ++ & +++ & - & +++ & ++ & ++ \\
\hline
\end{tabular}

Present (+) Absent (-), Chgz Sp.-Changzhou sample, Wx. Sp-Wuxi sample, CA- Cultured Algae.

\section{Total Flavonoids Content}

The various algae extract contains different amount of flavonoids as shown in Table 2, with the ultrasound assisted method resulting in high yield than conventional method. Total flavonoids content determined was found to be higher in the UAM extract than the conventional. This result then confirms the correlation between antioxidant activity, phenol and flavonoids contents. Thus, the antioxidant property of extracts can be anticipated based on its total phenols and flavonoids contents. Difference in quantity of total flavonoids seen can be as a result of the poor water solubility attributable to their phenolic nature. Some findings that reported high total polyphenol and total flavonoids substances in ultrasound assisted extract than conventional supports the drift found in the study ${ }^{[26]}$ As a result of the high amount of flavonoids in the extract a host of recurring and degenerative illnesses for example, cardiac diseases, vision impairment, memory lapses, cancer and Alzheimer's diseases, whose underlying condition is as a result of deficiency in the level of antioxidant, can be prohibited or hindered. ${ }^{[16]}$ Also, algae extract can be used to protect biological molecules (proteins) which are vulnerable to free radical damage.

\section{Chemical composition of Algae Extract}

The Fourier transform infrared spectra for the various algae samples are shown in Figure 2. FTIR is an important qualitative method of characterizing functional groups and their corresponding frequency. The various algae samples presented absorption peaks, the peak at $3400 \mathrm{~cm}^{-1}$ correspond to the stretching vibration of $\mathrm{O}-\mathrm{H}$ indicative of phenolic active compounds, while the peaks $2924 \mathrm{~cm}^{-1}$ and $2853 \mathrm{~cm}^{-1}$ can be accordingly ascribed to the stretching vibration of aliphatic and aromatic groups $(\mathrm{C}-\mathrm{H})$. At peak $1645 \mathrm{~cm}^{-1}$, the stretching vibration of aromatic ring $(\mathrm{C}=\mathrm{C})$, which is a distinctive absorption peak of phenyl. Peaks at $1088 \mathrm{~cm}^{-1}$ and $1383 \mathrm{~cm}^{-1}$ corresponds to $\mathrm{O}-\mathrm{H}$ bending of the biomolecule tannin. ${ }^{[32]}$ The stretching vibration of $\mathrm{C}-\mathrm{O}$ can be attributed to the peak at $1050 \mathrm{~cm}^{-1} \cdot{ }^{[33,34]}$ The presence of phytochemicals constituent in algae sample were established by the intense peaks above. The conventional extracted sample showed a peak at $833 \mathrm{~cm}^{-1}$ which corresponds with $\mathrm{C}-\mathrm{H}$ bending

\section{Scanning Electron Microscopic Analysis}

Figure 3 depicts the morphological differences of various algae samples before and after extraction with ultrasound. SEM was used to investigate the impact of extraction method on the structure of the algae cell. Figure 3 (a, i-iv) shows the microscopic structure of various algae samples before extraction and Figure 3 (b, i-iii) shows treated samples under optimal condition and Figure 3 (b, iv) for after treated with conventional method.

Table 2: Ultrasound assisted extraction and phytochemical content of different algae samples.

\begin{tabular}{|c|c|c|c|c|c|c|}
\hline \multirow[b]{2}{*}{ Algae } & & \multicolumn{5}{|c|}{ Phytochemicals } \\
\hline & Yield & $\begin{array}{l}\text { Flavonoid } \\
\text { (mg/g DW) }\end{array}$ & $\begin{array}{l}\text { Saponins } \\
\text { (mg/DW) }\end{array}$ & $\begin{array}{c}\text { Total phenol (mg/g } \\
\text { DW) }\end{array}$ & $\begin{array}{l}\text { Total Alkaloids } \\
\text { (mg/g DW) }\end{array}$ & $\begin{array}{r}\text { Total Tannic } \\
\text { (mg/g DW) }\end{array}$ \\
\hline Spirogyra & $19.51 \pm 0.37$ & $0.21 \pm 0.03$ & $18.70 \pm 2.78$ & $0.13 \pm 0.03$ & $1.15 \pm 0.03$ & $0.40 \pm 0.04$ \\
\hline Seaweed & $22.95 \pm 0.25$ & $0.13 \pm 0.05$ & $22.95 \pm 2.39$ & $0.11 \pm 0.07$ & $0.42 \pm 0.02$ & $0.17 \pm 0.06$ \\
\hline Changzhou sample & $27.00 \pm 0.50$ & $0.20 \pm 0.01$ & $24.30 \pm 1.82$ & $0.16 \pm 0.02$ & $1.74 \pm 0.01$ & $0.38 \pm 0.01$ \\
\hline Wuxi sample & $21.76 \pm 0.20$ & $0.12 \pm 0.06$ & $31.25 \pm 1.75$ & $0.16 \pm 0.05$ & $2.04 \pm 0.02$ & $0.28 \pm 0.07$ \\
\hline Cultured Algae & $23.33 \pm 0.40$ & $0.12 \pm 0.02$ & $20.21 \pm 1.86$ & $0.11 \pm 0.02$ & $1.24 \pm 0.04$ & $0.34 \pm 0.01$ \\
\hline Conventional & $18.61 \pm 0.30$ & $0.11 \pm 0.01$ & ND & $0.05 \pm 0.01$ & ND & $0.20 \pm 0.02$ \\
\hline
\end{tabular}

DW-Dry weight; ND: not determined. Values presented are a mean \pm SD of a triplicate extraction. 


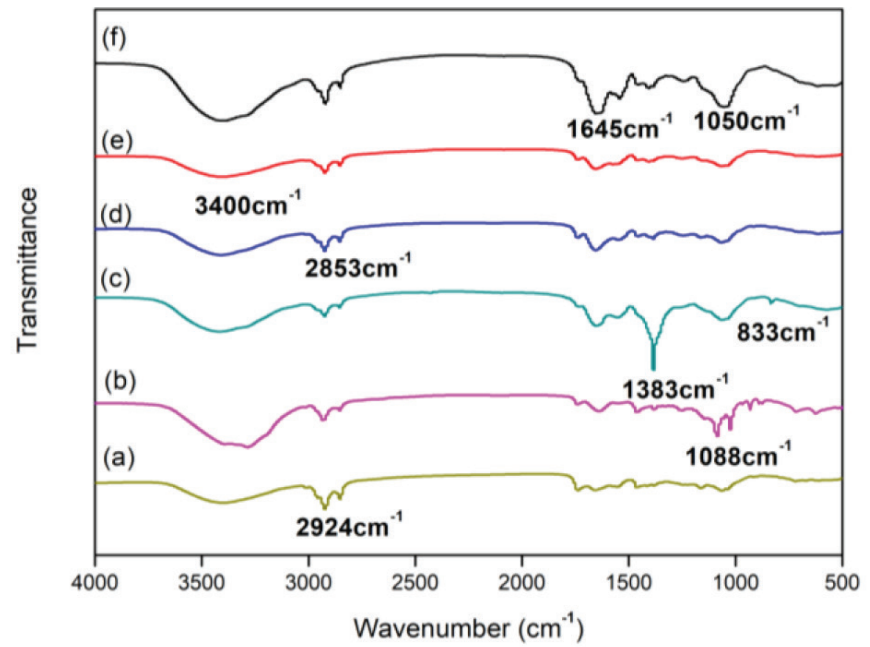

Figure 2: FTIR spectra of different algae extracts by UAM (a) Spirogyra (b) Seaweed (c) Cultured algae (d) Conventional extracted sample (e) Wuxi (f) Changzhou sample.
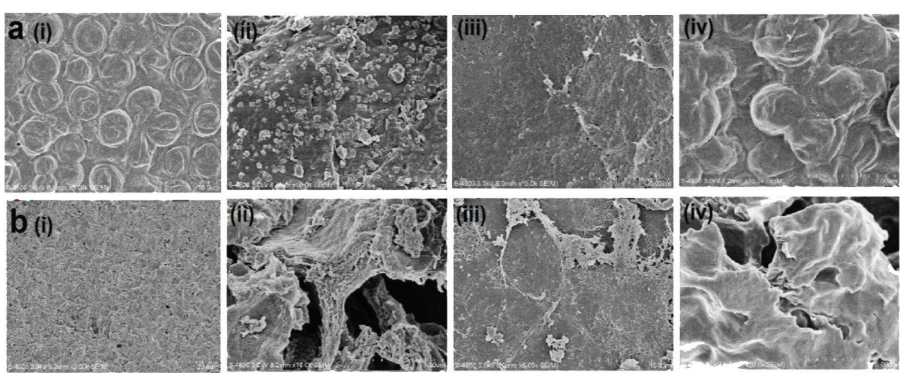

Figure 3: Scanning Electron Microscopic images of (a, i-iv) Dried untreated algae biomass and ( $b$, i-iii) Algae biomass after ultrasound treatment and (b, iv) biomass after Conventional extraction method.

It can be observed from the SEM images that the cell surface of the untreated algae samples are intact, unaltered and appear to be smooth. However, after undergoing treatment with the optimal ultrasound condition, images show increased porosity on the algal biomass as shown in Figure 3 (b, i-iii) explaining the high extraction yield in comparison to conventional method 3 (b, iv) which does not show changes to the surface of the biomass. Similar results with ultrasound were achieved by. ${ }^{[35,36]}$

\section{The thermal stabilities of various algae extract}

Figure 4 depicts the TGA and DTG of various algae samples leached with UAM. The residual weight $\%$ at $800^{\circ} \mathrm{C}$ was high for Wuxi sample, cultured algae, Seaweed, Changzhou sample algae sample and was low for Spirogyra. The algae biomass underwent three phases of weight loss, the evaporation of water in algal samples caused weight loss below $100^{\circ} \mathrm{C}$. As the temperature rises from 100 to $250^{\circ} \mathrm{C}$, the weight of various algae dropped slightly and the maximum weight loss was $10.46 \%$. The rapid weight loss from $250^{\circ} \mathrm{C}$ to elevated temperature was mainly attributed to the thermal decomposition of organic compounds and various algae sample powder for the second and third decomposition. The first and second decomposition peaks ensured around $240^{\circ} \mathrm{C}$ and $308.61^{\circ} \mathrm{C}$ respectively for spirogyra algae sample. On the other hand, the rapid weight loss for cultured algae sample might have ensured from the breakdown of more polysaccharide and protein content.
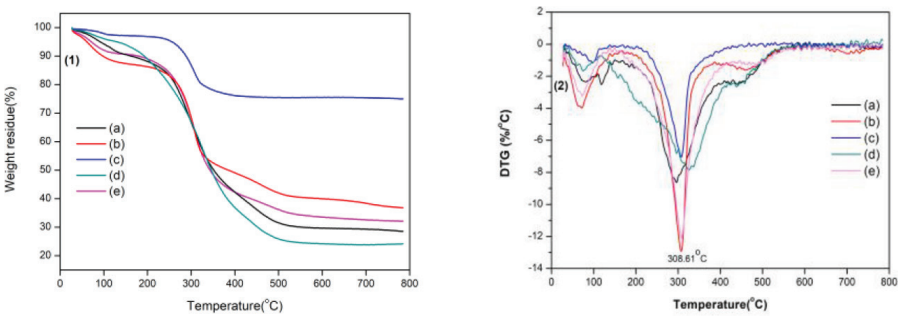

Figure 4: (1) Thermogravimetric analysis (TGA) and (2) Differential thermogravimetric (DTG) of various algae extracted by UAM (a) Wuxi sample (b) Cultured algae (c) Seaweed (d) Spirogyra (e) Changzhou sample.
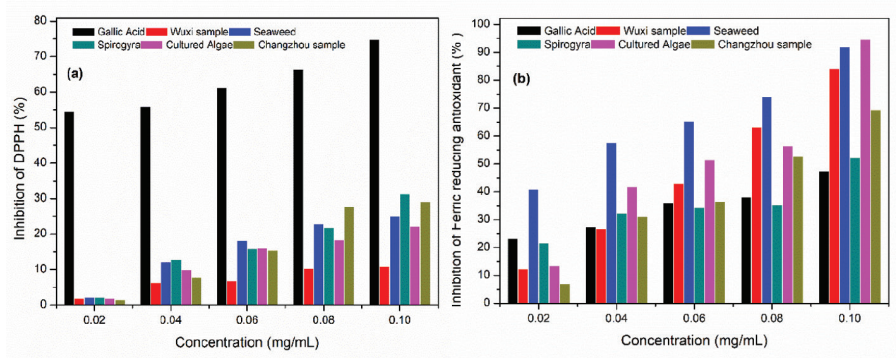

Figure 5: (a) DPPH scavenging activities for different algae extracts (b) Ferric reducing power of different algae extracts.

\section{Antioxidant activity of algae extracts Inhibition of DPPH Assay}

The algae extract shows substantial antioxidant activity in in vitro antioxidant assays. DPPH is a stable free radical often used in studies of phytochemical scavenging activity. Figure 5a shows the results of the algae extracts' DPPH scavenging activity in comparison to gallic acid as a reference standard. The stable deep violet DPPH radical is converted to a yellow DPPH after reacting with hydrogen donating antioxidants:

$$
\mathrm{DPPH} .+\mathrm{AH} \rightarrow \mathrm{DPPH}-\mathrm{H}+\mathrm{A} .
$$

As 2, 2-diphenyl-1-picrylhydrazyl radical takes on an electron in the presence of a free radical scavenger, the absorption drops ensuing in color change which is stoichiometrically proportional to the amount of electrons gained. ${ }^{[37]}$ DPPH activity was present in all of the algae extracts, but it was lower than the standard. Spirogyra extract shows higher activity almost paralleling seaweed and Changzhou sample. Changzhou sample seaweed, spirogyra and cultured algae extract showed increasing inhibition at high concentration of 0.08 and $0.1 \mathrm{mg} / \mathrm{ml}$. This finding is consistent with the total phenolic content of Changzhou extract, which was higher. DPPH-scavenging activity usually increases when total phenol content is high, ${ }^{[38]}$ Also, this result is in line with the findings of. ${ }^{[39]}$

\section{Ferric Reducing Power}

FRAP assay primarily measures a constituent's antioxidant ability as well as its reducing capacity in the reaction medium. Antioxidant activity was found to have a related and strong relationship with the reducing power in an assay, that been measured in the samples based on their potential to reduce $\mathrm{Fe}^{3+}$ complex to $\mathrm{Fe}^{2+}$. As the absorbance values increased, the extract's reducing capacity is shown to increase. Naturally occurring antioxidants are referred to as reductants and the process by which reductants inactivate oxidants is referred to as a redox reaction. 

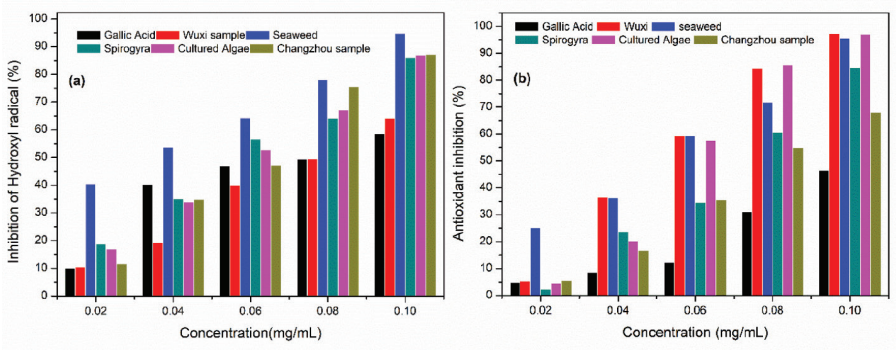

Figure 6: (a) Hydroxyl radical inhibition for different algal extracts (b) Total Antioxidant activity of different algae extracts.

[40] The results of the FRAP assay on different algae samples are shown in Figure 5b. As compared to the standard and other algae samples, the seaweed sample extracts had significantly higher FRAP values, followed by Cultured algae, Wuxi sample, Changzhou sample and spirogyra respectively. The present study's findings converge on the conclusion that seaweed extract has superior antioxidant properties to the other algae sample extracts. One possible explanation for the differences is that each algae sample accumulates different amounts of phytochemicals, which may influence the antioxidant levels present. The secondary metabolite intensities are known to be influenced by environmental factors such as water quality, season, geographic location, and mineral status which could also be contributing factor for yield differences. ${ }^{[1]}$

\section{Hydroxyl radical activity}

Figure $6 a$ shows the hydroxyl radical activity of algae samples and Gallic acid as standard. In comparison to the algae sample extracts, gallic acid had low hydroxyl radical activity with the exception of Wuxi sample. Formaldehyde was produced when hydroxyl radical generated in vitro utilizing ascorbic-acid-iron-EDTA solution reacted with DMSO. Formaldehyde formed produced a vibrant yellow color with Nash reagent when incubated for $15 \mathrm{~min}$,

$$
\text { HO. }+\left(\mathrm{CH}_{3}\right)_{2} \mathrm{SO} \rightarrow \mathrm{H}_{2} \mathrm{CO}+\text { Nash reagent }
$$

The vibrant yellow color created was spectroscopically read at $412 \mathrm{~nm} .^{[42]}$ In the presence of antioxidant, free hydroxyl radical is neutralized into water.

$$
\text { HO. }+\mathrm{AH} \rightarrow \mathrm{H}_{2} \mathrm{O}
$$

The most reactive oxygen-centered species, the hydroxyl radical, causes considerable damage to nearby biomolecules. In humans, the hydroxyl radical is known to damage cellular DNA, even minor DNA damage might render a cell susceptible to malignancy. ${ }^{[43]}$ The antioxidant activities of all of the measured samples seemed to be primarily linked to rising concentrations. When compared to the standard, the extracts had a lot more scavenging action.

\section{Total Antioxidant activity}

The presence of excessive reactive-oxygen species can cause lipid peroxidation, altering the structure of biomolecules in the body and resulting in cellular abnormalities, premature aging, mutations and cell death. Seaweed's antioxidant ability in vitro has been studied and attributed to the existence of novel antioxidant compounds such as carotenoids, polyphenols and certain polysaccharides, that exhibit scavenger activity, capable of neutralizing reactive oxygen species through self-oxidation, due to their strong affinity for those oxidative compounds. ${ }^{[44,45]}$ Standard evaluation techniques have been proposed to analyze the antioxidant capacity of plant extracts. Criteria employed to assess these methods include measurement of chemical processes that occur in possible uses, usage of biologically important molecules, available instrumentation, good reproducibility, adaptable for assays for both hydrophilic and lipophilic antioxidants and adaptability to rising assessment. ${ }^{[20]}$

Antioxidants act as reducing agents in the body, scavenging free radicals. They must possess some degree of antioxidant ability in order to function effectively and efficiently. The algae extracts had higher level of antioxidant capacity than the Gallic acid standard in a concentrationdependent manner. Among the various algae samples extracted, seaweed extract was found to contain high antioxidant level than Spirogyra, cultured, Wuxi and Changzhou sample (Figure 6b). Changzhou sample had the lowest antioxidant yield. As an essential phytochemical constituent phenol has shown a large potential for minimizing free radicals in the body, also functions as an antioxidant. ${ }^{[29]}$

The ultrasound assisted method of extraction presents the advantages of higher yield within a short time at low temperature, typically involves less solvent and is environmentally benignant in comparison to the conventional method. The UAM has an industrial potential to enhance production aside been used in the lab. The usage of UAM in lab and industry would create a link between lab scale test to the industrial pilot scale and increase the implementation of new ideas and methods.

\section{Bioactive compounds present in extracts and biochar from residue}

Table 3-5 lists the bioactive chemicals found in the various algal samples extracted with ethanol/water; their identification and characterization were premised on their elution sequence. The elution time, molecular weight and molecular formula. The GC chromatograms of the different extracts are shown in Figure 7. Indicating the observed peaks correspond to the chemical present in the extract and the retention duration in the column as indicated. The different crudes extract after GC-MS evaluation observed the presences of biologically active bioactive compounds, which supports algae species and can be applied as precursors in various fields. Dihydrochalcones exhibited inhibitory effect against cancer cells when evaluated in in vitro conditions and are also known for their antidiabetic effect. Dihydrochalcones are a secondary metabolite, with demand in biological and multivariate pharmacological properties, such as antidiabetic, lipometabolism regulating, anti-inflammatory, antibacterial, antiviral, and immunomodulatory properties. ${ }^{[46,47]}$ Synthesized derivatives of Benzamide, and derivatives of $\mathrm{N}-(1 \mathrm{H}-$ benzimidazol-2-yl) -2-mercaptoacetamide proved effective as antifungal when compared with standard drug ketoconazole and inhibited against P. aeruginos ${ }^{[48]}$ vibrio fluvialis can be inhibited by Benzenecarbothioic acid. ${ }^{[49]}$

The algae antioxidant properties might ensure from the presence of pigments such as chlorophylls, carotenoids, vitamins and vitamin precursors namely niacin, cophenol, thiamine, ascorbic acid and phenolic compounds like polyphenols, hydroquinone and flavonoids. Phospholipids and other antioxidant substances contribute to the oxidation process inhibition. ${ }^{[49]}$ An earlier study showed the antimicrobial and antifungal activity algal extract against several pathogens. ${ }^{[50]}$ It is worth noting that the extracting solvent also contributes to the compounds extracted. The presences of the large number of useful metabolites in these algae species, makes them of phytopharmaceuticals importance. The identification of these compounds makes the different algae samples a great source of bioactive compounds.

The residue after extraction was converted into biochar, which also proved good at adsorption, for removal of pollutants as shown in Figure 8 and can also be used in the agricultural sector for plant growth. 
Table 3: Chemical constituent of crude extract of Changzhou sample.

\begin{tabular}{|c|c|c|c|}
\hline Name of compounds & Retention time & Molecular formula & Molecular weight \\
\hline 3-Ethoxy-1,1,1,7,7,7-hexamethyl-3,5,5-tris (trimethylsiloxy) tetrasiloxane & 15.85 & $\mathrm{C}_{17} \mathrm{H}_{50} \mathrm{O}_{7} \mathrm{Si}_{7}$ & 562 \\
\hline $\mathrm{N}$-(Methylsulfonyl)-N, O-bis (trimethylsilyl) hydroxylamine & 15.87 & $\mathrm{C}_{7} \mathrm{H}_{21} \mathrm{NO}_{3} \mathrm{SSi}_{2}$ & 255 \\
\hline $\mathrm{N}$-(Trifluoroacetyl)-N, O, O, O"-tetrakis (trimethylsilyl) norepinephrine & 20.16 & $\mathrm{C}_{22} \mathrm{H}_{4} \mathrm{~F}_{3} \mathrm{NO}_{4} \mathrm{Si}_{4}$ & 553 \\
\hline 3-Ethoxy-1,1,1,7,7,7-hexamethyl-3,5,5-tris(trimethylsiloxy)tetrasiloxane & 22.53 & $\mathrm{C}_{17} \mathrm{H}_{50} \mathrm{O}_{7} \mathrm{Si}_{7}$ & 562 \\
\hline 3-Isopropoxy-1,1,1,7,7,7-hexamethyl-3,5,5-tris(trimethylsiloxy)tetrasiloxane & 22.55 & $\mathrm{C}_{18} \mathrm{H}_{52} \mathrm{O}_{7} \mathrm{Si}_{7}$ & 576 \\
\hline 1,3,5-Triphenyl-1,5-pentanedione & 24.49 & $\mathrm{C}_{23} \mathrm{H}_{20} \mathrm{O}_{2}$ & 328 \\
\hline 1-Penten-3-ol,4,4-dimethyl-1,3diphenyl- & 24.50 & $\mathrm{C}_{19} \mathrm{H}_{22} \mathrm{O}$ & 266 \\
\hline 2-Propen-1-one,1,3-diphenyl-, phenylhydrazone & 25.99 & $\mathrm{C}_{21} \mathrm{H}_{18} \mathrm{~N}_{2}$ & 298 \\
\hline 1,3-Di(4-methylphenyl)-2,2-dibenzylpropane & & $\mathrm{C}_{31} \mathrm{H}_{32}$ & 404 \\
\hline Xylopyranoside, methyl 4-thio-, tribenzoate, alpha-D- & 27.91 & $\mathrm{C}_{27} \mathrm{H}_{24} \mathrm{O}_{7} \mathrm{~S}$ & 492 \\
\hline (4Z)-4-(3,4-Dimethoxybenzylidene)-2-phenyl-1,3-oxazol-5(4H)-one & & $\mathrm{C}_{18} \mathrm{H}_{15} \mathrm{NO}_{4}$ & 309 \\
\hline
\end{tabular}

Table 4: Chemical constituent of crude extract of Spirogyra sample.

\begin{tabular}{cccc}
\hline Name of compounds & $\begin{array}{c}\text { Retention } \\
\text { time }\end{array}$ & $\begin{array}{c}\text { Molecular } \\
\text { formula }\end{array}$ & $\begin{array}{c}\text { Molecular } \\
\text { weight }\end{array}$ \\
\hline $\begin{array}{c}\text { Heptane,2,5,5-trimethyl } \\
\text { Oxalic acid, dineopentyl ester } \\
\text { Benzenecarbothioic acid, } \\
\text { S-propyl ester. }\end{array}$ & 22.51 & $\mathrm{C}_{10} \mathrm{H}_{22}$ & 142 \\
$\begin{array}{c}\text { 1,2,3-Butanetrione, 1-phenyl-, } \\
\text { 2,3-dioxime }\end{array}$ & 23.48 & $\mathrm{C}_{10} \mathrm{H}_{22} \mathrm{O}_{4}$ & 230 \\
$\mathrm{C}_{10} \mathrm{H}_{12} \mathrm{OS}$ & 180 \\
$\begin{array}{c}\text { Benzamide,N-1H-benzimidazol- } \\
\text { 2-yl-2-hydroxyl. }\end{array}$ & 33.43 & $\mathrm{C}_{10} \mathrm{H}_{10} \mathrm{~N}_{2} \mathrm{O}_{3}$ & 206 \\
$\begin{array}{c}\text { Phthalic acid, di(3,4- } \\
\text { dimethylphenyl) ester }\end{array}$ & 33.44 & $\mathrm{C}_{11} \mathrm{~N}_{3} \mathrm{O}_{2}$ & 253 \\
$\begin{array}{c}\text { Propanoic acid, anhydride } \\
\text { Thiolane-3,3,4,4- }\end{array}$ & 37.50 & $\mathrm{C}_{6} \mathrm{H}_{10} \mathrm{O}_{3}$ & 374 \\
tetracarbonitrile, 2,5-di-tert- \\
butyl
\end{tabular}

Table 5: Chemical constituent of crude extract of Seaweed sample.

\begin{tabular}{cccc}
\hline Name of compounds & $\begin{array}{c}\text { Retention } \\
\text { time }\end{array}$ & $\begin{array}{c}\text { Molecular } \\
\text { formula }\end{array}$ & $\begin{array}{c}\text { Molecular } \\
\text { weight }\end{array}$ \\
\hline 1,3,5- Triphenyl-1,5-pentanedione & 28.07 & $\mathrm{C}_{23} \mathrm{H}_{20} \mathrm{O}_{2}$ & 328 \\
2-Propen-1-one,1,2-diphenyl- & 28.09 & $\mathrm{C}_{15} \mathrm{H}_{12} \mathrm{O}$ & 208 \\
$\begin{array}{c}\text { Acetic acid, 2-benzoylamino-2- } \\
\text { phenyl-, propyl ester }\end{array}$ & 29.06 & $\mathrm{C}_{18} \mathrm{H}_{19} \mathrm{NO}_{3}$ & 297 \\
Beta-phenylpropiophenone, & 29.08 & $\mathrm{C}_{15} \mathrm{H}_{14} \mathrm{O}$ & 210 \\
\hline
\end{tabular}

\section{CONCLUSION}

The findings of this study showed that spirogyra, seaweed, Changzhou sample, Wuxi sample, and cultured algae samples all possess a variety of phytochemical constituents that can effectively boost the immune system against free radical's oxidative stress and serve as a natural source effective bioactive constituent. In terms of yield and time, the study found that ultrasound extraction is a more effective and environmentally benignant method of extracting bioactive compounds than the traditional method. The use of these various algae as sources of phytochemical and antioxidant compounds will increase their value and encourage them as alternative sources. The biochar made after extraction proves the complete utilization of algae biomass.

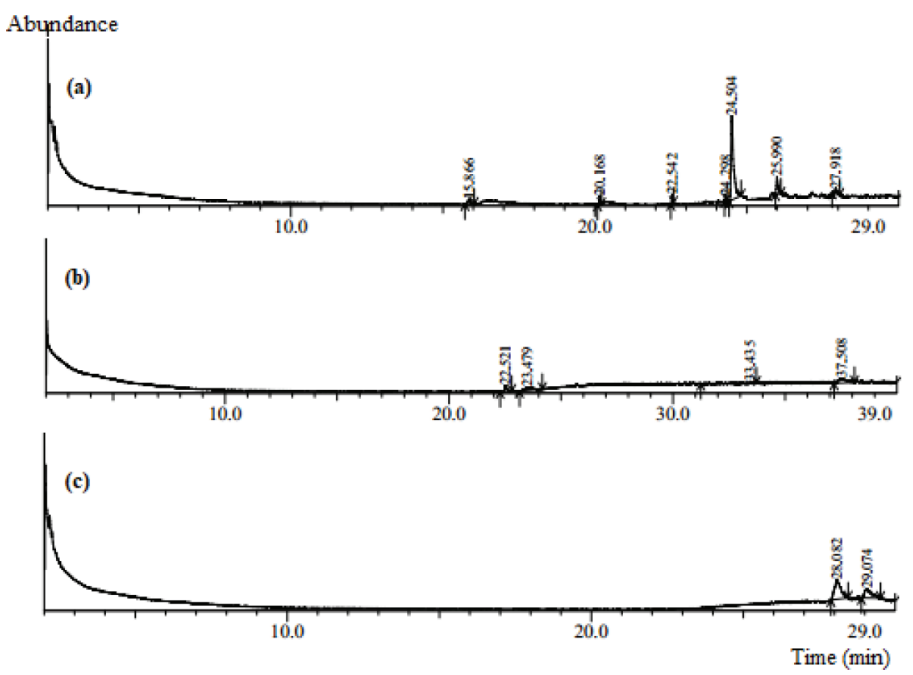

Figure 7: (i) GC-MS chromatogram of bioactive compounds present in extracts of (a) Changzhou sample crude extracts(b) Spirogyra crude extracts (c)Seaweed crude extracts. (ii) Biochar made from algae residue after extraction for adsorption of Methylene blue.
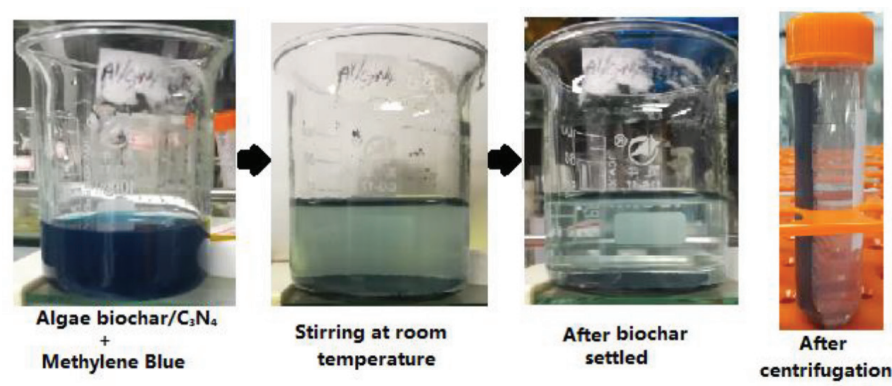

Figure 8: Biochar made from algae residue after extraction for adsorption of Methylene blue.

\section{ACKNOWLEDGEMENT}

This work was supported jointly by the Key Program of the National Natural Science Foundation of China (Grant No.51779079, 51979137), the Natural Science Foundation of Jiangsu Province (Grant No. BK20181313), the Project Funded by the Priority Academic Program Development of Jiangsu Higher Education Institutions (PAPD), Jiangsu 
Wizi, et al.: Analysis of Bioactive Compounds from Different Algae Samples

Water Conservancy Science and Technology Project (2018037), and the Top-notch Academic Programs Project of Jiangsu Higher Education Institutions (TAPP).

\section{CONFLICT OF INTEREST}

The authors declare that there is no conflict of interest.

\section{ABBREVIATIONS}

UAM: Ultrasonic assisted method; CM: conventional method; CA: Cultured algae; SEM: Scanning Electron Microscopic; GC-MS: Gas chromatography-mass spectrometry; TCA: trichloroacetic acid; EDTA: Ethylenediaminetetraacetic acid; DMSO: Dimethyl sulfoxide; DNA: Deoxyribonucleic acid; DPPH: 1,1-diphenyl-2-picrylhydrazyl; FRAP: Ferric reducing antioxidant property.

\section{SUMMARY}

In this study, different algae samples were subjected to ultrasound treatment with solvent mixture of $70 \%$ ethanol and $30 \%$ water $(\mathrm{v} / \mathrm{v})$. Microcystis aeruginosa, Spirogyra, Seaweed and algae from lake Taihu were treated with ultrasound. The analysis revealed the presence of bioactive compounds such as alkaloids, phenols, tannins, flavonoids, terpenoids, steroids, proteins, carbohydrates, phytosterols, quinones, saponins, coumarins and glycosides among the different algae samples. In vitro screening of the extracts also showed good antioxidant capacity (hydroxyl radical $(\bullet \mathrm{OH})$ scavenging activity, ferric reducing antioxidant property (FRAP), 1, 1diphenyl2picrylhydrazyl (DPPH) scavenging activity), the extracted compounds are of biological and pharmacological importance. The study showed the different algae species were enriched with phytochemicals, which have inhibitory effect against various ailments and have potential in pharmaceutical products. Biochar was produced from the residue after extraction ensuring the complete utilization of algae biomass.

\section{REFERENCES}

1. Aravind S, Barik D, Ragupathi P, Vignesh G. Investigation on algae oil extraction from algae Spirogyra by Soxhlet extraction method. Mater Today Proc. 2021.

2. Bhowmick S, Mazumdar A, Moulick A, Adam V. Algal metabolites: An inevitable substitute for antibiotics. Biotechnol Adv. 2020;43:107571. doi: 10.1016/j. biotechadv.2020.107571, PMID 32505655.

3. Tang DYY, Khoo KS, Chew KW, Tao Y, Ho SH, Show PL. Potential utilization of bioproducts from microalgae for the quality enhancement of natural products. Bioresour Technol. 2020;304:122997. doi: 10.1016/j.biortech.2020.122997, PMID 32094007.

4. Savvidou MG, Sotiroudis TG, Kolisis FN. Cell surface and cellular debrisassociated heat-stable lipolytic enzyme activities of the marine alga Nannochloropsis oceanica. Biocatal Biotransform. 2016;34(1):24-32. doi: 10.1080/10242422.2016.1212843.

5. Brasil BSAF, Silva FCP, Siqueira FG. Microalgae biorefineries: The Brazilian scenario in perspective. N Biotechnol. 2017;39(A):90-8. doi: 10.1016/j. nbt.2016.04.007, PMID 27343427.

6. Luo $X$, Su $P$, Zhang W. Advances in microalgae-derived phytosterols for functional food and pharmaceutical applications. Mar Drugs. 2015;13(7):4231-54 doi: 10.3390/md13074231, PMID 26184233.

7. Wizi J, Wang L, Hou X, Tao Y, Ma B, Yang Y. Ultrasound-microwave assisted extraction of natural colorants from sorghum husk with different solvents. Ind Crops Prod. 2018;120:203-13. doi: 10.1016/j.indcrop.2018.04.068.

8. Duval J, Pecher V, Poujol M, Lesellier E. Research advances for the extraction, analysis and uses of anthraquinones: A review. Ind Crops Prod. 2016;94:812-33. doi: 10.1016/j.indcrop.2016.09.056.

9. Barros F, Dykes L, Awika JM, Rooney LW. Accelerated solvent extraction of phenolic compounds from sorghum brans. J Cereal Sci. 2013;58(2):305-12. doi: 10.1016/j.jcs.2013.05.011

10. Hou F, Su D, Xu J, Gong Y, Zhang R, Wei Z, et al. Enhanced extraction of phenolics and antioxidant capacity from sorghum (Sorghum bicolor L. Moench) shell using ultrasonic-assisted ethanol-water binary solvent. J Food Process Preserv. 2016;40(6):1171-9. doi: 10.1111/jfpp.12699.
11. Akogou FU, Kayodé AP, Den Besten HM, Linnemann AR. Extraction methods and food uses of a natural red colorant from dye sorghum. J Sci Food Agric 2018:98(1):361-8. doi: 10.1002/jsfa.8479, PMID 28600852

12. Sivakumar $V$, Vijaeeswarri J, Anna JL. Effective natural dye extraction from different plant materials using ultrasound. Ind Crops Prod. 2011;33(1):116-22. doi: 10.1016/j.indcrop.2010.09.007.

13. Barizão ÉO, Boeing JS, Martins AC, Visentainer JV, Almeida VC. Application of response surface methodology for the optimization of ultrasound-assisted extraction of pomegranate (Punica granatum L.) seed oil. Food Anal Methods. 2015;8(9):2392-400. doi: 10.1007/s12161-015-0135-5.

14. Wu X, Jiang J, Hu J. Determination and occurrence of retinoids in a eutrophic lake (Taihu Lake, China): Cyanobacteria blooms produce teratogenic retinal. Environ Sci Technol. 2013:47(2):807-14. doi: 10.1021/es303582u, PMID 23256639.

15. Paterson. Phytochemical methods. A guide to modern techniques of plant analysis. J B Harborne. 15x 23.4 cm, 302 pp. London: Chapman and Hall, 1988. Price f. ISBN 0-412-57260 (hardback). Plant Pathol. 1999;48(1).

16. Darkwah WK, Ao Y, Adinortey MB, Weremfo A, Abrokwah FK, Afriyie E. Total phenolic, flavonoid and alkaloid contents, oxidative DNA damage protective and antioxidant properties of methanol and aqueous extracts of Dissotis rotundifolia whole plant. Free Radic Antioxid. 2018;8(2):82-8. doi: 10.5530/fra.2018.2.13.

17. Alvarez-Suarez JM, Tulipani S, Díaz D, EstevezY, Romandini S, Giampieri F, et al Antioxidant and antimicrobial capacity of several monofloral Cuban honeys and their correlation with color, polyphenol content and other chemical compounds. Food Chem Toxicol. 2010;48(8-9):2490-9. doi: 10.1016/j.fct.2010.06.021, PMID 20558231

18. Peri $C$, Pompei $C$. Estimation of different phenolic groups in vegetable extracts Phytochemistry. 1971;10(9):2187-9. doi: 10.1016/S0031-9422(00)97216-9.

19. Bankole $A E$, Uchendu $E E$, Adekunle AA. In vitro germination of Markhamia tomentosa Benth K. Schum ex. Engl. and preliminary phytochemical screening for medicinal compounds. Ind J Plant Physiol. 2017;22(1):85-93. doi: 10.1007/ s40502-016-0279-3.

20. Prior RL, Wu X, Schaich K. Standardized methods for the determination of antioxidant capacity and phenolics in foods and dietary supplements. J Agric Food Chem. 2005;53(10):4290-302. doi: 10.1021/jf0502698, PMID 15884874

21. Oyaizu M. Studies on products of browning reaction. Antioxidative activities of products of browning reaction prepared from glucosamine. Jpn J Nutr Diet. 1986;44(6):307-15. doi: 10.5264/eiyogakuzashi.44.307.

22. Shimada K, Fujikawa K, Yahara K, Nakamura T. Antioxidative properties of xanthan on the autoxidation of soybean oil in cyclodextrin emulsion. J Agric Food Chem. 1992;40(6):945-8. doi: 10.1021/jf00018a005

23. Sasikumar V. Evaluation of free radical scavenging activity of various leaf extracts from Kedrostis foetidissima (Jacq.) Cogn.,. Biochem Anal Biochem. 2014;03(2). doi: 10.4172/2161-1009.1000150.

24. Amin M, Chetpattananondh P. Biochar from extracted marine Chlorella $\mathrm{sp}$. residue for high efficiency adsorption with ultrasonication to remove $\mathrm{Cr}(\mathrm{VI}), \mathrm{Zn}(\mathrm{II})$ and Ni(II). Bioresour Technol. 2019:289:121578. doi: 10.1016/]. biortech.2019.121578, PMID 31195297.

25. Holkar CR, Jadhav AJ, Bhavsar PS, Kannan S, Pinjari DV, Pandit AB. Acoustic cavitation assisted alkaline hydrolysis of wool based keratins to produce organic amendment fertilizers. ACS Sustainable Chem Eng. 2016;4(5):2789-96. doi: 10.1021/acssuschemeng.6b00298.

26. Ummat V, Tiwari BK, Jaiswal AK, Condon K, Garcia-Vaquero M, O'Doherty J et al. Optimisation of ultrasound frequency, extraction time and solvent for the recovery of polyphenols, phlorotannins and associated antioxidant activity from brown seaweeds. Mar Drugs. 2020;18(5). doi: 10.3390/md18050250, PMID 32403273.

27. Barkia I, Saari N, Manning SR. Microalgae for high-value products towards human health and nutrition. Mar Drugs. 2019;17(5). doi: 10.3390/md17050304, PMID 31137657

28. Vinholes J, Vizzotto M. Synergisms in alpha-glucosidase inhibition and antioxidant activity of Camellia sinensis L. Kuntze and Eugenia uniflora L. ethanolic Extracts. Pharmacogn Res. 2017;9(1):101-7. doi: 10.4103/09748490.197797, PMID 28250662.

29. Biney E, Nkoom M, Darkwah W, Puplampu J. High-performance liquid chromatography analysis and antioxidant activities of extract of Azadirachta indica (Neem) leaves. Pharmacogn Res. 2020;12(1).

30. Sabeena Farvin $\mathrm{KH}$, Jacobsen C. Phenolic compounds and antioxidant activities of selected species of seaweeds from Danish coast. Food Chem. 2013;138(2-3): 1670-81. doi: 10.1016/j.foodchem.2012.10.078, PMID 23411297.

31. De Oliveira AMF, Pinheiro LS, Pereira CKS, Matias WN, Gomes RA, Chaves OS et al. Total phenolic content and antioxidant activity of some Malvaceae family species. Antioxidants. 2012;1(1)

32. Rufus A, Sreeju N, Vilas V, Philip D. Biosynthesis of hematite ( $\alpha$-Fe2O3) nanostructures: Size effects on applications in thermal conductivity, catalysis, and antibacterial activity. J Mol Liq. 2017;242:537-49. doi: 10.1016/i. molliq.2017.07.057.

33. Benabbouha T, Nmila R, Siniti M, Chefira K, El Attari H, Rchid H. The brown algae Cystoseira baccata extract as a friendly corrosion inhibitor on carbon steel in acidic media. SN Appl Sci. 2020;2(4). doi: 10.1007/s42452-020-2492-y. 
34. Saxena A, Prasad D, Haldhar R, Singh G, Kumar A. Use of Sida cordifolia extract as green corrosion inhibitor for mild steel in $0.5 \mathrm{M} \mathrm{H} 2 \mathrm{SO} 4$. J Environ Chem Eng. 2018;6(1):694-700. doi: 10.1016/j.jece.2017.12.064.

35. Garcia-Vaquero M, Ummat V, Tiwari B, Rajauria G. Exploring ultrasound, microwave and ultrasound-microwave assisted extraction technologies to increase the extraction of bioactive compounds and antioxidants from brown macroalgae. Mar Drugs. 2020;18(3). doi: 10.3390/md18030172, PMID 32244865.

36. Liew SQ, Ngoh GC, Yusoff R, Teoh WH. Sequential ultrasound-microwave assisted acid extraction (UMAE) of pectin from pomelo peels. Int J Biol Macromol. 2016;93(A):426-35. doi: 10.1016/j.ijbiomac.2016.08.065, PMID 27565298.

37. Zhang G, He L, Hu M. Optimized ultrasonic-assisted extraction of flavonoids from Prunella vulgaris $L$. and evaluation of antioxidant activities in vitro. Innov Food Sci Emerg Technol. 2011;12(1):18-25. doi: 10.1016/j.ifset.2010.12.003.

38. Nandhakumar $E$, Indumathi $P$. In vitro antioxidant activities of methanol and aqueous extract of Annona squamosa (L.) fruit pulp. J Acupunct Meridian Stud. 2013;6(3):142-8. doi: 10.1016/j.jams.2012.09.002, PMID 23787283.

39. Hemwimol S, Pavasant $P$, Shotipruk A. Ultrasound-assisted extraction of anthraquinones from roots of Morinda citrifolia. Ultrason Sonochem. 2006;13(6):543-8. doi: 10.1016/j.ultsonch.2005.09.009, PMID 16325453.

40. Shahidi F, Zhong Y. Measurement of antioxidant activity. J Funct Foods. 2015;18:757-81. doi: 10.1016/j.jff.2015.01.047.

41. Bachheti A, Deepti BRK, Husen A. Medicinal plants and their pharmaceutical properties under adverse environmental conditions. Harsh Environ Plant Resil. 2021.

42. Dhandapani KV, Anbumani D, Gandhi AD, Annamalai P, Muthuvenkatachalam BS, Kavitha $\mathrm{P}$, et al. Green route for the synthesis of zinc oxide nanoparticles from
Melia azedarach leaf extract and evaluation of their antioxidant and antibacterial activities. Biocatal Agric Biotechnol. 2020;24. doi: 10.1016/j.bcab.2020.101517.

43. Guha G, Rajkumar V, Mathew L, Kumar RA. The antioxidant and DNA protection potential of Indian tribal medicinal plants. Turk J Biol. 2011;35(2).

44. Gomez-Zavaglia A, Prieto Lage MA, Jimenez-Lopez C, Mejuto JC, SimalGandara J. The potential of seaweeds as a source of functional ingredients of prebiotic and antioxidant value. Antioxidants (Basel). 2019;8(9). doi: 10.3390/ antiox8090406, PMID 31533320.

45. Martínez Andrade KA, Lauritano C, Romano G, lanora A. Marine microalgae with anti-cancer properties. Mar Drugs. 2018;16(5). doi: 10.3390/md16050165, PMID 29762545.

46. Stompor M, Broda D, Bajek-Bil A. Dihydrochalcones: Methods of Acquisition and Pharmacological Properties-A First Systematic Review. Molecules. 2019;24(24). doi: 10.3390/molecules24244468. PMID 31817526.

47. Szliszka E, Czuba ZP, Mazur B, Paradysz A, Krol W. Chalcones and dihydrochalcones augment TRAIL-mediated apoptosis in prostate cancer cells. Molecules. 2010;15(8):5336-53. doi: 10.3390/molecules15085336, PMID 20714300.

48. Yilmaz G. Antimicrobial activity of some Centaurium hill taxa growing in turkey. Ank Univ Eczacilik Fak Derg;44(3):415-23. doi: 10.33483/jfpau.756312.

49. Mohy El-Din SM, El-Ahwany AMD. Bioactivity and phytochemical constituents of marine red seaweeds (Jania rubens, Corallina mediterranea and Pterocladia capillacea). J Taibah Univ Sci. 2016;10(4):471-84. doi: 10.1016/j. jtusci.2015.06.004.

50. Wefky S, Ghobrial M. Studies on the bioactivity of different solvents extracts of selected marine macroalgae against fish pathogens. Res $\mathrm{J}$ Microbiol. 2008;3(12).

GRAPHICAL ABSTRACT

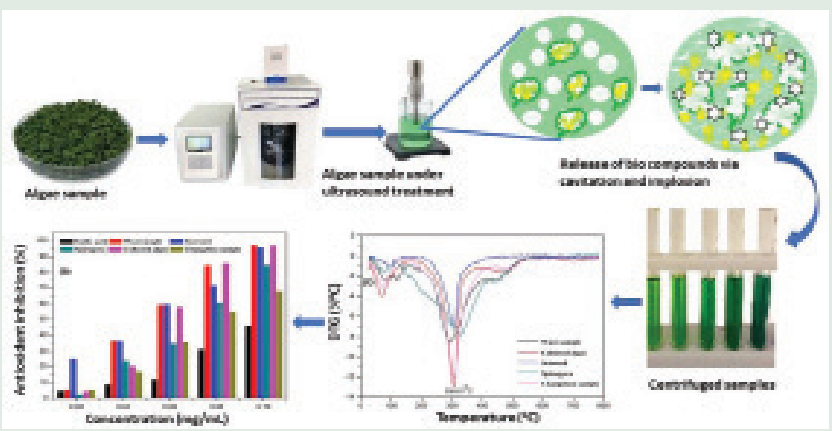

Cite this article: Wizi J, Ni L, Darkwah WK, Xianglan L. Analysis of Bioactive Compounds from Different Algae Samples Extracted with Ultrasound: Characterizations, Phytochemical Contents and Antioxidant Potentials. Pharmacog Res. 2022;14(1):35-44. 